\title{
Traumatic Brain Injury: Effect of Litigation Status on Executive Functioning-A Pilot Study
}

\author{
Simi Prakash K ${ }^{1} \quad$ Rajakumari P. Reddy, \\ ${ }^{1}$ Department of Clinical Psychology, National Institute of Mental \\ Health \& Neurosciences, Karnataka, India \\ ${ }^{2}$ Department of Clinical Psychology, National Institute of Mental \\ Health \& Neurosciences Karnataka, India \\ ${ }^{3}$ Department of Clinical Psychology, National Institute of Mental \\ Health \& Neurosciences, Karnataka, India \\ ${ }^{4}$ Neurosurgery, National Institute of Mental Health \& \\ Neurosciences, Karnataka, India
}

\author{
Anna R. Mathulla $a^{3, \odot}$
}

\author{
Address for correspondence Rajakumari P. Reddy, PhD, \\ Department of Clinical Psychology, National Institute of Mental \\ Health \& Neurosciences (NIMHANS), Hosur Road, Bengaluru, \\ Karnataka 560029, India (e-mail: rajkumari227@yahoo.com).
}

\begin{abstract}
Keywords

- executive functions

- traumatic brain injury

- cognitive impairment

- working memory

- litigation status

Traumatic brain injury (TBI) is associated with a wide range of physiological, behavioral, emotional, and cognitive sequelae. Litigation status is one of the many factors that has an impact on recovery. The aim of this study was to compare executive functions, postconcussion, and depressive symptoms in TBI patients with and without litigation. A sample of 30 patients with TBI, 15 patients with litigation (medicolegal case [MLC]), and 15 without litigation (non-MLC) was assessed. The tools used were sociodemographic and clinical proforma, executive function tests, Rivermead Post-Concussion Symptom Questionnaire, and Beck Depression Inventory. Assessment revealed that more than $50 \%$ of patients showed deficits in category fluency, set shifting, and concept formation. The MLC group showed significant impairment on verbal working memory in comparison to the non-MLC group. The performance of both groups was comparable on tests of semantic fluency, visuospatial working memory, concept formation, set shifting, planning, and response inhibition. The MLC group showed more verbal working memory deficits in the absence of significant postconcussion and depressive symptoms on self-report measures.
\end{abstract}

\section{Introduction}

Traumatic brain injury (TBI) is a condition that affects millions world over; it affects global public health leading to permanent disabilities, decrease in life expectancy, and increase in mortality rates. A single traumatic insult or repetitive insults can lead to seizures, sleep disorders, neurodegenerative diseases, neuroendocrine dysregulation, or psychiatric disorders. Impaired consciousness and posttraumatic amnesia (PTA) are the typical neurobehavioral presentations of TBI. Moderate and severe TBI are characterized by loss of consciousness for greater than 30 minutes and/or PTA persisting for 24 hours. ${ }^{1}$ The extent and degree of the sequelae depend on the severity and location of the injury, presence of concomitant injuries, and chronicity of the injury. Patient variables such as age, neuropsychiatric history, genotype, and quality of the acute environment postinjury can mitigate the cognitive effects. Other factors such as pain, work status, litigation status, and support also play an important role in recovery. ${ }^{1,2}$ The postconcussion syndrome refers to a constellation of somatic, cognitive, and emotional symptoms following TBI. ${ }^{3}$ In mild-to-moderate TBI, the commonly affected functions are memory, attention, processing speed, and executive functions that usually resolve within 3 to 6 months. However, in moderate-to-severe TBI there are deficits in published online

October 5, 2020
DoI https://doi.org/

10.1055/s-0040-1717214 ISSN 0973-0508.
C2020. Neurotrauma Society of India.

This is an open access article published by Thieme under the terms of the Creative Commons Attribution-NonDerivative-NonCommercial-License, permitting copying and reproduction so long as the original work is given appropriate credit. Contents may not be used for commercial purposes, or adapted, remixed, transformed or built upon. (https://creativecommons.org/licenses/by-nc-nd/4.0/).

Thieme Medical and Scientific Publishers Pvt. Ltd. A-12, 2nd Floor, Sector 2, Noida-201301 UP, India 
memory, attention, processing speed, executive functions as well as impairments in communication, visuospatial processing, intellectual ability, and insight. Nearly half of those with TBI experience major depressive disorder in the first year. The severity of brain injury is associated with unfavorable outcomes including decreased social activity and unemployment and reduced quality of life and suicide. ${ }^{4}$ There is a decrease in the mortality rates in TBI, as a result of better awareness, improved traffic safety measures, proper clinical guidelines, and advanced patient care. There is a greater need for the management and compensation of individuals with TBI-related disabilities. ${ }^{5}$ Litigation is a prominent and consistent factor accounting for poor outcome and prolonged recovery from $\mathrm{TBI}$.

\section{Neuropsychological Studies in TBI}

Sigurdardotti et $\mathrm{al}^{6}$ studied the cognitive impairment in a sample of 105 persons with severe TBI. The result showed that at 1-year postinjury, executive functions, processing speed, and memory were impaired. Metting et $\mathrm{al}^{7}$ found impairments in immediate memory, attention, processing speed, executive functions, and emotion recognition in patients with mild TBI. Barker-Collo et $\mathrm{al}^{8}$ examined and found impairments in psychomotor speed, cognitive processing speed, and executive abilities in patients with mild TBI. Executive abilities and speed were related to postconcussion symptoms, mood, and self-reported cognitive disturbances. Fasli Sidheek ${ }^{9}$ in 2014 found significant deficits in social cognition along with neurocognitive deficits in patients with TBI. Konrad et a ${ }^{10}$ investigated long-term cognitive and emotional sequelae in mild traumatic brain injury (mTBI). Results showed significant impairments in all cognitive domains and depressive symptoms in patients with mTBI. Dikmen et $\mathrm{al}^{11}$ examined rates of symptom reporting following TBI. It was significantly related to age, gender, preinjury alcohol abuse, preinjury psychiatric history, and severity of TBI. Over all, studies have found that patients with mild TBI had impairments in immediate memory, attention, speed, and executive functions. However, there were significant improvements in cognition, post-concussion symptoms, depression, anxiety over the 12 months postinjury. Binder et $\mathrm{al}^{12}$ conducted a meta-analysis to study relationship between mild traumatic brain injury (mTBI) and cognitive functioning in individuals assessed more than 3 months postinjury. They found a significant but small effect in the area of attention and concentration, suggesting that attention measures might be the most sensitive to persistent neuropsychological dysfunction after mTBI. The severity of injury accounted for most variance than a specific neuropsychological domain. Binder ${ }^{13}$ also found that 7 to $8 \%$ of mTBI patients had chronic symptoms and $14 \%$ were occupationally disabled. Imaging studies of acutely injured persons may show lesions and it is likely that the effects of these lesions dissipate with time, as shown by neuropsychological findings. Data also suggested that mTBI patients had more psychosocial problems prior to injury. In addition to the neurological basis for sustained cognitive sequelae, one cannot dismiss alternative medical or psychiatric explanations for persisting complaints. As a follow-up to the above study, Frencham et $\mathrm{al}^{14} \mathrm{did}$ a meta-analytic review of subsequent neuropsychological studies in mTBI and included data collected at any stage postinjury. Their study showed that speed of processing, working memory, attention, memory, and executive function were most sensitive to dysfunction in individuals after mTBI, with memory being particularly affected in the acute phase, and showing resolution with time since injury. The effects of mTBI on neuropsychological functioning were small, and in general, reduced to levels comparable with nonhead injured individuals after the first 3 months.

\section{Litigation Studies in TBI}

Subrahmanyam and Agrawal ${ }^{15}$ in 2012 studied the medicolegal issues faced by TBI patients in India. They explored the consequences of TBI and the medicolegal issues associated with it. They elaborated on the medicolegal guidelines and duties of medical personnel such as recording dying declaration, taking consent, recording of all relevant data, counselling significant others, attending court summons, and providing all relevant information accurately in court. This article highlights the need for expert medical advice in relation to criminal, insurance, personal injury, and negligence issues. Tsanadis et al in $2008^{16} \mathrm{did}$ an archival study to explore the frequency of postconcussion symptoms in moderate-to-severe TBI and compared it to mild TBI with poor effort. They found that the mild TBI cases reported significantly higher degree of psychological, cognitive, and somatic symptoms. Individuals who were in litigation and failed effort tests reported more postconcussive symptoms compared with individuals with moderate-to-severe TBI, who were also undergoing litigation. Woods et $\mathrm{al}^{17}$ in a study used computerized trail-making test (TMT) to evaluate the effect of aging, malingering, and TBI on performance. The computerized version increased the precision and replicability of the TMT, by permitting a segment-by-segment analysis of performance and separate analyses of dwell-time, move-time, and error time. Malingering subjects showed greater increases on the C-TMT-A than on the C-TMT-B, while TBI patients showed the opposite pattern. TBI patients produced slowed completion times on the C-TMT-B and reduced movement velocities on both the C-TMT-A and C-TMT-B. A total of $40 \%$ base rate of poor effort/test invalidity in personal injury cases was found. Matsuzawa and Dijkers ${ }^{18}$ did a qualitative study to understand, the factors associated with the distress experienced by TBI litigants. They focused on the domains of cognitive, emotional, physical, psychosocial functioning, and coping strategies. The following themes emerged from interviews, litigants felt stagnation, the time-consuming nature of litigation interfered with the process of recovery. Subjects felt confused and found it difficult to comprehend the complex demands of litigation. They felt misunderstood, discredited, and doubted. Felt having to constantly demonstrate their impairments. Litigation was found to cause significant distress and dissatisfaction. They further explored how TBI litigants facilitated well-being and recovery during and after the litigation process. Psychosocial support, emotional support as well as psychoeducation were 
found to be useful. Compensatory strategies for the cognitive and emotional difficulties were also helpful. ${ }^{19}$

With an estimated 10 million people affected annually by TBI, the burden that this condition imposes on society makes it a pressing public health problem. With the increasing number of patients who pursue litigation and seek compensation, there is a demand for comprehensive assessment and reporting in the field of clinical/forensic psychology. In India, there are limited studies that look into the effect of litigation on the neuropsychological functioning, presence of postconcussion symptoms, depression or malingering in TBI patients with medicolegal cases.

The objectives of the study were as follows:

1. To evaluate whether there is a difference in the executive functions of TBI patients with and without litigation.

2. To assess whether there is a difference in self-report measures of postconcussion and depressive symptoms, between TBI patients with and without litigation.

3. To evaluate whether executive functions are correlated to postconcussion symptoms and depressive symptoms in TBI patients.

\section{Materials and Methods}

Research Design: A cross-sectional, single assessment, research design was adopted for the study.

Participants: Patients were recruited from the neurosurgery outpatient services, during the period of June 2017 to March 2017. A sample of 30 TBI patients was selected. The sampling technique used was convenience sampling. The inclusion criteria were patients in the age range of 18 to 50 years, right-handed persons, with ability to read and write, and 3 months to 2 years duration post-TBI. Those with a history of posttraumatic epilepsy, major psychiatric disorders, neurological disorders, or neurosurgical conditions other than head injury, clinical evidence of mental retardation, surgery, substance dependence and those with severe sensorimotor or language deficits were excluded from the study. The clinical details such as severity and duration of TBI were obtained from patients and medical record files. The cause for TBI in the sample was road traffic accidents. The severity was determined using Glasgow Coma Scale (GCS) scores (mild: 13-15; moderate: 9-12; severe: 3-8). The sample consisted of mild and moderate TBI patients. Majority of the patients ( $84 \%$ ) belonged to the mild TBI category.

\section{Materials}

Sociodemographic and Clinical Proforma: A sociodemographic and clinical proforma was prepared to record demographic details such as age, gender, and socioeconomic status as well as details of illness and treatment.

The following executive function tests were taken from the NIMHANS Neuropsychology Battery (2004).

1. Animal Names Test ${ }^{20}$ : Subjects were required to generate the names of as many animals as possible in 1 minute. The subject is asked to exclude the names of fish, birds, and snakes. The number of names generated is the score.
2. Verbal Working Memory N Back Test ${ }^{21}$ : The test consists of two parts: 1 back and 2 back. Thirty randomly ordered consonants are read out. In the 1 back test, the subject is asked to tap, whenever a consonant is repeated consecutively. While in the 2 back test, the subject has to tap, whenever a consonant is repeated after an intervening consonant. The number of correct responses (hits) and errors are noted.

3. Spatial Span Test ${ }^{22}$ : The spatial span test assesses the visuospatial working memory. The test consists of a board with 10 blocks of the same size. The examiner taps the blocks in a predetermined order, following which the subject has to tap the blocks in the same order. In the backward condition, the subject is required to tap the blocks in reverse order.

4. Tower of London Test ${ }^{23}$ : The test consists of two identical wooden boards with three wooden balls, painted red, green, and blue, respectively. The subject is presented with a goal state of arrangement using the three balls on the board placed near the examiner. The subject has tried to arrange the balls on their board, like that of the examiner, using a minimum number of moves. Total number of moves are noted.

5. Wisconsin Card Sorting Test ${ }^{24}$ : This test examines concept formation, abstract reasoning, and set shifting ability. The test consists of two sets of 64 cards and 4 stimulus cards with different geometrical figures (triangle, star, cross, circle) in different colors (red, green, yellow, blue) and in different numbers (one, two, three, four shapes).The subject is required to match and sort the cards according to a particular principle (color, form or number).

6. Stroop Test ${ }^{25}$ : In this test, the color names blue, green, red, and yellow are printed in capital letters on a paper. The color of the print intermittently corresponds with the color designated by the word. The subject is asked to read the stimuli, column wise as fast as possible followed by naming the color in which the word is printed. The time taken to read the words minus the time taken to name the colors is the score.

The following self-report measures were used to assess postconcussion symptoms and depressions symptoms:

\section{Rivermead Post Concussion Symptom Questionnaire (RPQ $)^{26}$}

The RPQ consists of 16 of the most commonly reported postconcussion symptoms. The patients are asked to rate the degree to which they experienced the symptoms as compared with their premorbid levels functioning.

2. Beck Depression Inventory (BPI) ${ }^{27}$ :The BDI is a 21 -item self-report rating inventory that measures characteristic attitudes and symptoms of depression. The BDI takes $\sim 10$ minutes to complete.

The tests were administered for patients who met the inclusion criteria and who gave written informed consent for participation. Testing was performed over a period of 2 hours, with adequate rest periods.

Data Analysis: The results were analyzed using descriptive and inferential statistics such as mean, standard deviation, and $t$-tests for continuous variables and frequency and 
percentages for qualitative variables. The executive function assessment data was analyzed using nonparametric tests (Mann-Whitney U test). A $p$-value $<0.05$ was considered to be statistically significant.

Ethical Considerations: The study was initiated after necessary approvals were received from the Internal Ethics Committee. Patients were informed about the nature of the study. Confidentiality and anonymity were assured and maintained. They were informed that participation in the study would be voluntary. Any identification or disclosure of mental health concerns resulted in appropriate referrals to clinical services.

\section{Results}

\section{Sociodemographic Variables}

The sociodemographic variables are presented in - Table $\mathbf{1}$. The mean age and number of years of education of both medicolegal case (MLC) and non-MLC groups were comparable. A comparison of sociodemographic variables between the MLC and non-MLC groups was performed, in terms of school versus college educated, employment status, and marital status. Both MLC and non-MLC groups did not differ significantly in terms of education, employment, and marital status.

\section{Executive Functions in MLC and Non-MLC Groups}

The results of the executive function tests indicated impairments in semantic fluency, concept formation, set shifting, response inhibition, planning, verbal and visuospatial working memory. On comparing the executive functions of the MLC and non-MLC groups ( - Table 2 ), it was found that there was a significant difference in the domain of verbal working memory ( $\mathrm{N}$ Back test-2) on both hits $(p=0.041)$ and errors $(p=0.044)$.The non-MLC group had more hits and lesser errors. The performance of both groups was comparable on semantic fluency, visuospatial working memory, concept formation, set shifting, planning and response inhibition $(p>0.05)$.
Overall results of the executive function tests indicated significantly poor performance on verbal working memory by the MLC group as compared with the non-MLC group.

\section{Postconcussion Symptoms and Depressive Symptoms in the MLC and Non-MLC Groups.}

The results showed that the MLC patients and non-MLC patients reported similarly on both postconcussion symptoms and depressive symptoms. There was no significant difference between the two groups for postconcussion symptoms $(p=0.472)$ and depression $(p=0.873)$. The scores on the postconcussion symptom questionnaire (cutoff score $\geq 16$ ) and BDI (cutoff score $<13$ ) showed that patients in the both groups were asymptomatic. The performance on the executive function tests of both the MLC and non-MLC groups were correlated (two-tailed Spearman rank correlation) with the scores on the RPQ and the BDI. In the MLC group, it was found that a higher visuospatial span was negatively correlated to postconcussion symptoms $(r=0.578)$ as well as symptoms of depression $(r=0.569)$. In the non-MLC group, there was no significant correlation between executive functions, postconcussion symptoms, and depression symptoms.

\section{Discussion}

\section{Sociodemographic and Clinical Details}

Sociodemographic variables of age, education, gender, marital status, occupation, and socioeconomic status were obtained. The male-female ratio of the sample was 13:2, and majority of patients were males. According to the Centers for Disease Control and Prevention, males are 3.4 times more likely to obtain TBI. The current sample is indicative of the gender disparity when it comes to TBI. The sample obtained was comparable in terms of age and education. There was no statistical difference between both groups regarding marital status and employment. However, it may be noted that the MLC group comprised of more unemployed individuals. This

Table 1 Comparison of the sociodemographic variables of MLC and non-MLC groups

\begin{tabular}{|c|c|c|c|c|c|c|}
\hline \multirow{2}{*}{\multicolumn{2}{|c|}{ Sociodemographic Variables }} & \multicolumn{2}{|c|}{$\operatorname{MLC}(n=15)$} & \multicolumn{2}{|c|}{ Non-MLC $(n=15)$} & \multirow[t]{2}{*}{$p$-Value } \\
\hline & & Mean & SD & Mean & SD & \\
\hline \multicolumn{2}{|l|}{ Age (y) } & 33.13 & 9.37 & 8.66 & 32.93 & 0.952 \\
\hline \multicolumn{2}{|l|}{ Education (y) } & 10.73 & 2.815 & 4.079 & 13.07 & 0.0769 \\
\hline \multirow{2}{*}{\multicolumn{2}{|c|}{ Sociodemographic variables }} & \multicolumn{2}{|c|}{$\operatorname{MLC}(n=15)$} & \multicolumn{2}{|c|}{ Non-MLC $(n=15)$} & \multirow[t]{2}{*}{$p$-Value } \\
\hline & & $n$ & $\%$ & $n$ & $\%$ & \\
\hline \multirow[t]{2}{*}{ Education } & School & 11 & 73.3 & 7 & 46.7 & \multirow[t]{2}{*}{0.264} \\
\hline & College & 4 & 26.7 & 8 & 53.3 & \\
\hline \multirow[t]{2}{*}{ Employment } & Employed & 5 & 33.3 & 11 & 73.3 & \multirow[t]{2}{*}{0.066} \\
\hline & Unemployed & 10 & 66.7 & 4 & 26.7 & \\
\hline \multirow[t]{3}{*}{ Marital status } & Married & 6 & 40 & 9 & 60 & \multirow[t]{3}{*}{0.489} \\
\hline & Unmarried & 6 & 40 & 5 & 33.3 & \\
\hline & Separated & 3 & 20 & 1 & 6.7 & \\
\hline
\end{tabular}

Abbreviations: MLC, medicolegal case; SD, standard deviation. 
Table 2 Comparison of executive functions in the MLC and non-MLC groups

\begin{tabular}{|c|c|c|c|c|}
\hline Tests & Group ( $n=15$ each) & Median & $\begin{array}{l}\text { Mann-Whitney } \\
\text { U test }\end{array}$ & Sig. \\
\hline \multicolumn{5}{|l|}{ Category fluency } \\
\hline \multirow[t]{2}{*}{ ANT } & MLC group & $8(10-6)$ & \multirow[t]{2}{*}{101.5} & \multirow[t]{2}{*}{0.647} \\
\hline & Non-MLC group & $10(14-3)$ & & \\
\hline \multicolumn{5}{|l|}{ Verbal working memory } \\
\hline \multirow{2}{*}{$\begin{array}{l}\text { N-back test } \\
1 \text { Back Hits }\end{array}$} & MLC group & $7(9-6)$ & \multirow[t]{2}{*}{85.5} & \multirow[t]{2}{*}{0.247} \\
\hline & Non-MLC group & $8(9-7)$ & & \\
\hline \multirow{2}{*}{$\begin{array}{l}\text { N-back test } \\
1 \text { Back Errors }\end{array}$} & MLC group & $1(3-0)$ & \multirow[t]{2}{*}{100.5} & \multirow[t]{2}{*}{0.609} \\
\hline & Non-MLC group & $1(2-1)$ & & \\
\hline \multirow{2}{*}{$\begin{array}{l}\text { N-back test } \\
2 \text { Back Hits }\end{array}$} & MLC group & $4(6-4)$ & \multirow[t]{2}{*}{64} & \multirow[t]{2}{*}{0.041} \\
\hline & Non-MLC group & $8(8-6)$ & & \\
\hline \multirow{2}{*}{$\begin{array}{l}\text { N-back test } \\
2 \text { Back Errors }\end{array}$} & MLC group & $5(6-4)$ & \multirow[t]{2}{*}{64.5} & \multirow[t]{2}{*}{0.044} \\
\hline & Non-MLC group & $3(5-1)$ & & \\
\hline \multicolumn{5}{|l|}{ Visuospatial working memory } \\
\hline \multirow[t]{2}{*}{ Spatial span test } & MLC group & $14(16-8)$ & \multirow[t]{2}{*}{107} & \multirow[t]{2}{*}{0.386} \\
\hline & Non-MLC group & $14(16-10)$ & & \\
\hline \multicolumn{5}{|l|}{ Concept formation, set shifting } \\
\hline \multirow{2}{*}{$\begin{array}{l}\text { WCST } \\
\text { No. of correct responses }\end{array}$} & MLC group & $90(95-40)$ & \multirow[t]{2}{*}{108} & \multirow[t]{2}{*}{0.852} \\
\hline & Non-MLC group & $68(70-54)$ & & \\
\hline \multirow{2}{*}{$\begin{array}{l}\text { WCST } \\
\text { Perseverative response (\%) }\end{array}$} & MLC group & $35(46-29)$ & \multirow[t]{2}{*}{76} & \multirow[t]{2}{*}{0.130} \\
\hline & Non-MLC group & $26(41-22)$ & & \\
\hline \multirow{2}{*}{$\begin{array}{l}\text { WCST } \\
\text { Conceptual level responses (\%) }\end{array}$} & MLC group & $27(44-11)$ & \multirow[t]{2}{*}{81.5} & \multirow[t]{2}{*}{0.198} \\
\hline & Non-MLC group & $41(52-26)$ & & \\
\hline WCST & MLC group & $1(1-0)$ & 92.5 & 0.386 \\
\hline & Non-MLC group & $1(2-0)$ & & \\
\hline Planning & & & & \\
\hline TOL & MLC group & $10(13-7)$ & 108.5 & 0.867 \\
\hline Total no. of moves & Non-MLC group & $9(13-6)$ & & \\
\hline Response inhibition & & & & \\
\hline Stroop test (time taken) & MLC group & $241(418-124)$ & 93 & 0.419 \\
\hline & Non-MLC group & $166(269-135)$ & & \\
\hline
\end{tabular}

Abbreviations: ANT, animal name test; MLC, medicolegal case; WCST, Wisconsin Card Sorting Test; TOL, Tower of London.

finding further poses the question whether unemployment was a result of injury and disability, and could warrant the need for compensation. Majority of patients in both groups were from the middle socioeconomic status.

\section{Executive Functioning in TBI}

The neurobehavioral changes associated with TBI can persist for months or even years after the injury and has a significant impact on the quality of life of patients. The frontal lobes and their related circuitry are particularly vulnerable to traumatic damage. Hence, executive dysfunction deficits are common following TBI, even among those with mild TBI. ${ }^{1,28-}$ ${ }^{30}$ Executive functions can be defined as "the ability to maintain an appropriate problem solving set, for the attainment of future goals. Executive functions involve, an intention to inhibit a response or to defer it to a later appropriate time; a strategic plan of action sequence; a mental representation of the task, including the relevant stimulus information encoded into memory and the desired future goal state." ${ }^{31}$ The executive functions measured in the current study are category fluency, verbal and visual working memory, planning, set shifting, and response inhibition. While comparing the executive functions of both groups, it was found that the MLC group performed poorer than the non-MLC group on the verbal working memory task. This was consistent with several studies, which implicate individuals involved in litigation following TBI tend to report more symptoms postinjury, and perform worse on neurocognitive measures, than do nonlitigants. ${ }^{32,33}$ According to McAllister et al, ${ }^{34}$ one of the most common neuropsychological deficits seen in TBI occurs in the domain of working memory. Functional imaging studies in healthy individuals have shown that regions 
important in the working memory circuitry overlap with regions commonly vulnerable to damage in TBI. It may be associated with decreased activation in the dorsolateral prefrontal cortex; evidence also suggests that subtle alterations in central catecholaminergic sensitivity may underlie these problems. ${ }^{35}$ Tsanadis et al ${ }^{16}$ found that individuals who had mild brain injury, who were in litigation and failed effort tests, reported more post concussive symptoms compared with the group of individuals with moderate-to-severe TBI, who were also undergoing litigation. These findings indicate that subjective complaints following mild TBI may be a result of non-neurological factors.

\section{Postconcussion Symptoms and Depressive Symptoms}

The present study showed that there was no significant difference in both MLC and non-MLC groups in postconcussion symptoms and depressive symptoms. Neither of the groups met the criteria for postconcussion or depressive symptoms on self-report measures. This finding is consistent with results reported by Ponsford et al. ${ }^{36}$ that suggest fairly low mean frequency scores for both patients with mild TBI and patients with minor injuries. In general, cognitive deficits associated with mild TBI resolve fully within 3 to 6 months, in $~ 80$ to $85 \%$ of patients. Though some patients appear to demonstrate cognitive complaints, ${ }^{1}$ the precise prevalence and etiology of these sequelae remain unclear. In the MLC group, there was significant negative correlation between visuospatial working memory and symptoms of postconcussion and depressive symptoms. It was found that a higher spatial span was correlated with lesser postconcussion and depressive symptoms on RPQ and BDI respectively. In the non-MLC group, there was no significant correlation between executive functions, postconcussion symptoms, and depressive symptoms. Working memory functions have been reported to be associated with postconcussion symptoms, after head trauma. ${ }^{37,38}$ Several studies implicate working memory impairment in patients with depressive symptoms. ${ }^{39,40}$

\section{Conclusion}

Neuropsychological assessment was performed for 30 patients with TBI. The sample consisted of 15 TBI patients with litigation and 15 patients without litigation. The sample was comparable for sociodemographic variables. At the time of clinical evaluation, the subjects were able to comprehend test instructions and there was nil significant history of developmental, psychiatric, or neurological disorders. The executive function assessment showed that more than $50 \%$ of the TBI patients showed deficits in category fluency, set shifting, and concept formation. On comparison of both groups, the MLC group showed significant impairment on verbal working memory. The performance of both groups was comparable on semantic fluency, visuospatial working memory, concept formation, set shifting, planning, and response inhibition. Both groups of patients did not show significant postconcussion and depressive symptoms on self-report measures. The MLC group showed more verbal working memory deficits. This could indicate that individuals undergoing litigation do experience residual cognitive deficits, which may interfere with recovery and impact activities of daily living. Matsuzawa and Dijkers ${ }^{18}$ in a qualitative study found that TBI patients who undergo litigation felt misunderstood, discredited, and doubted. Litigants felt a need to constantly demonstrate the impairment and disability caused by Injury. Litigation in itself was found to cause significant distress and dissatisfaction to patients and was a barrier in the recovery process. At times, repeated questioning from doctors and lawyers can focus a person's attention on symptoms that otherwise would have spontaneously resolved that in turn can lead to maintenance and reinforcement of illness behavior. There is also the possibility of secondary gains being associated with the continued presence of symptoms and disability. In view of the emergent cognitive profiles in patients of TBI with and without litigation, there is a need for the development and implementation of cognitive retraining programs and strategies addressing the executive function deficits, which will aid in successful reintegration of patients into society. However, this study does have limitations such as a small sample size, the use of convenient sampling method, lack of information regarding premorbid functioning and the sample does include both mild and moderate TBI patients, thus limiting the generalization of the results. Future research could focus on neuropsychological functioning, effort, and performance validity testing. In addition, evaluating psychological factors such as premorbid personality and functioning, social support would give a better perspective. A randomized controlled design, robust analysis, a larger sample, and imaging would yield a comprehensive understanding and would benefit TBI patients, who undergo the medicolegal process. When conducting neuropsychological assessments in medicolegal examinations, one must consider the need to assess for effort and motivation to rule out exaggeration of cognitive disability. While litigation is pursued, specific compensatory strategies, psychoeducation, and psychosocial support should be considered for TBI patients to minimize the associated distress and to ensure smooth recovery.

\section{Conflict of Interest}

None declared.

\section{References}

1 Rabinowitz AR, Levin HS. Cognitive sequelae of traumatic brain injury. Psychiatr Clin North Am 2014;37(1):1-11

2 Podell K, Gifford K, Bougakov D, Goldberg E. Neuropsychological assessment in traumatic brain injury. Psychiatr Clin North Am 2010;33(4):855-876

3 Alexander MP. Mild traumatic brain injury: pathophysiology, natural history, and clinical management. Neurology 1995;45(7):1253-1260

4 Hart T, Hoffman JM, Pretz C, Kennedy R, Clark AN, Brenner LA. A longitudinal study of major and minor depression following traumatic brain injury. Arch Phys Med Rehabil 2012;93(8):1343-1349

5 Galgano M, Toshkezi G, Qiu X, Russell T, Chin L, Zhao LR. Traumatic brain injury: current treatment strategies and future endeavors. Cell Transplant 2017;26(7):1118-1130 
6 Sigurdardotti S, Andelic N, Wehling E, et al. Neuropsychological functioning in a national cohort of severe traumatic brain injury: demographic and acute injury related predictors. J Head Trauma Rehabil 2015;30(2):1-12

7 Metting Z, Spikman JM, Rödiger LA, van der Naalt J. Cerebral perfusion and neuropsychological follow up in mild traumatic brain injury: acute versus chronic disturbances? Brain Cogn 2014;86:24-31

8 Barker-Collo S, Jones K, Theadom A, et al; BIONIC Research Group. Neuropsychological outcome and its correlates in the first year after adult mild traumatic brain injury: a population-based New Zealand study. Brain Inj 2015;29(13-14):1604-1616

9 Fasli Sidheek KP. Neuropsychological functioning, social cognition and emotion perception in traumatic brain injury (MPhil. Dissertation). Bengaluru, India: National Institute of Mental Health and Neurosciences; 2014

10 Konrad C, Geburek AJ, Rist F, et al. Long-term cognitive and emotional consequences of mild traumatic brain injury. Psychol Med 2011;41(6):1197-1211

11 Dikmen SS, Corrigan JD, Levin HS, Machamer J, Stiers W, Weisskopf MG. Cognitive outcome following traumatic brain injury. J Head Trauma Rehabil 2009;24(6):430-438

12 Binder LM, Rohling ML, Larrabee GJ. A review of mild head trauma. Part I: meta-analytic review of neuropsychological studies. J Clin Exp Neuropsychol 1997a;19(3):421-431

13 Binder LM. A review of mild head trauma. Part II: clinical implications. J Clin Exp Neuropsychol 1997b;19(3):432-457

14 Frencham KAR, Fox AM, Maybery MT. Neuropsychological studies of mild traumatic brain injury: a meta-analytic review of research since 1995. J Clin Exp Neuropsychol 2005;27(3):334-351

15 Subrahmanyam BV, Agrawal A. Medico-legal issues in patients of traumatic brain: Indian perspective. Indian J Neurotrauma 2012;9(2):117-122

16 Tsanadis J, Montoya E, Hanks RA, Millis SR, Fichtenberg NL, Axelrod BN. Brain injury severity, litigation status, and self-report of postconcussive symptoms. Clin Neuropsychol 2008;22(6):1080-1092

17 Woods DL, Wyma JM, Herron TJ, Yund EW. The effects of aging, malingering, and traumatic brain injury on computerized trail-making test performance. PLoS One 2015;10(6):e0124345

18 Matsuzawa YK, Dijkers MP. The experience of litigation after TBI. I: barriers to recovery. Psychol Inj Law 2014a;7:388-396

19 Matsuzawa YK, Dijkers MP. The experience of litigation after TBI. II: coping with litigation after TBI. Psychol Inj Law 2014b;8:88-93

20 Lezak MD, Neuropsychological Assessment. 3rd edition. New York: Oxford University Press; 1995: 611

21 Smith EE, Jonides J. Storage and executive processes in the frontal lobes. Science 1999;283(5408):1657-1661

22 Milner B. Interhemispheric differences in the localization of psychological processes in man. Br Med Bull 1971;27(3): 272-277
23 Shallice T. Specific impairments of planning. Philos Trans R Soc Lond B Biol Sci 1982;298(1089):199-209

24 Heaton RK, Chelune GJ, Talley JL, Kay GG, Curtiss G, Wisconsin Card Sorting Test Manual-Revised and Expanded. Odessa FL: Psychological Assessment Resources Inc; 1993

25 Rao SL, Subbakrishna DK, Gopakumar K, NIMHANS Neuropsychology Battery. Bangalore: NIMHANS Publication; 2004

26 King NS, Crawford S, Wenden FJ, Moss NEG, Wade DT. The Rivermead Post Concussion Symptoms Questionnaire: a measure of symptoms commonly experienced after head injury and its reliability. J Neurol 1995;242(9):587-592

27 Beck AT, Steer RA, Manual for the Beck Depression Inventory. San Antonio, TX: Psychological Corp; 1993

28 TroyerAK, Moscovitch M,WinocurG.Clustering and switchingas two components of verbal fluency: evidence from younger and older healthy adults. Neuropsychology 1997;11(1):138-146

29 Busch RM, McBride A, Curtiss G, Vanderploeg RD. The components of executive functioning in traumatic brain injury. J Clin Exp Neuropsychol 2005;27(8):1022-1032

30 Vanderploeg RD, Curtiss G, Belanger HG. Long-term neuropsychological outcomes following mild traumatic brain injury. J Int Neuropsychol Soc 2005;11(3):228-236

31 Pennington BF, Ozonoff S. Executive functions and developmental psychopathology. J Child Psychol Psychiatry 1996; 37(1):51-87

32 Carroll LJ, Cassidy JD, Peloso PM, et al; WHO Collaborating Centre Task Force on Mild Traumatic Brain Injury. Prognosis for mild traumatic brain injury: results of the WHO Collaborating Centre Task Force on Mild Traumatic Brain Injury. J Rehabil Med 2004;36(43,Suppl):84-105

33 Lees-Haley PR, Brown RS. Neuropsychological complaint base rates of 170 personal injury claimants. Arch Clin Neuropsychol 1993;8(3):203-209

34 McAllister TW, Flashman LA, McDonald BC, Saykin AJ. Mechanisms of working memory dysfunction after mild and moderate TBI: evidence from functional MRI and neurogenetics. (Abstract) J Neurotrauma 2006;23(10):1450-1467

35 McAllister TW. Neurobiological consequences of traumatic brain injury. Dialogues Clin Neurosci 2011;13(3):287-300

36 Ponsford J, Willmott C, Rothwell A, et al. Factors influencing outcome following mild traumatic brain injury in adults. J Int Neuropsychol Soc 2000;6(5):568-579

37 King NS. Post-concussion syndrome: clarity amid the controversy? Br J Psychiatry 2003;183(4):276-278

38 Dean PJA, Sterr A. Long-term effects of mild traumatic brain injury on cognitive performance. Front Hum Neurosci 2013;7:30

39 Channon S, Green PSS. Executive function in depression: the role of performance strategies in aiding depressed and nondepressed participants. J Neurol Neurosurg Psychiatry 1999; 66(2):162-171

40 Hartlage S, Alloy LB, Vázquez C, Dykman B. Automatic and effortful processing in depression. Psychol Bull 1993; 113(2):247-278 